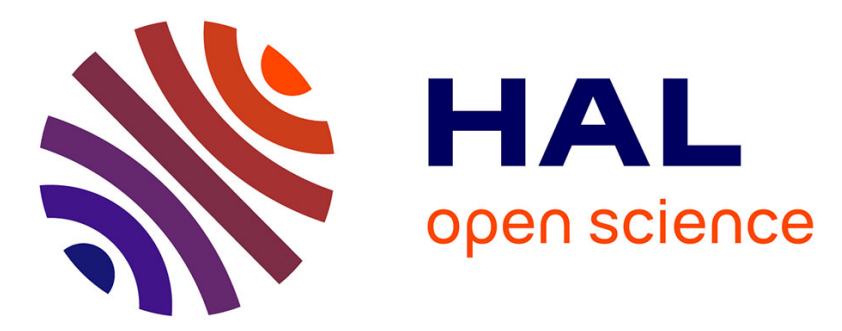

\title{
Microstructure and self-heating for ferritic steels under cyclic loading at low stress magnitudes
}

\author{
Véronique Favier, Charles Mareau, André Galtier, Bastien Weber, Marcel
} Berveiller

\section{- To cite this version:}

Véronique Favier, Charles Mareau, André Galtier, Bastien Weber, Marcel Berveiller. Microstructure and self-heating for ferritic steels under cyclic loading at low stress magnitudes. Metallurgical Research \& Technology, 2010, 107 (1), pp.3-8. 10.1051/metal/2010005 . hal-02458274

\section{HAL Id: hal-02458274 https://hal.science/hal-02458274}

Submitted on 28 Jan 2020

HAL is a multi-disciplinary open access archive for the deposit and dissemination of scientific research documents, whether they are published or not. The documents may come from teaching and research institutions in France or abroad, or from public or private research centers.
L'archive ouverte pluridisciplinaire HAL, est destinée au dépôt et à la diffusion de documents scientifiques de niveau recherche, publiés ou non, émanant des établissements d'enseignement et de recherche français ou étrangers, des laboratoires publics ou privés. 


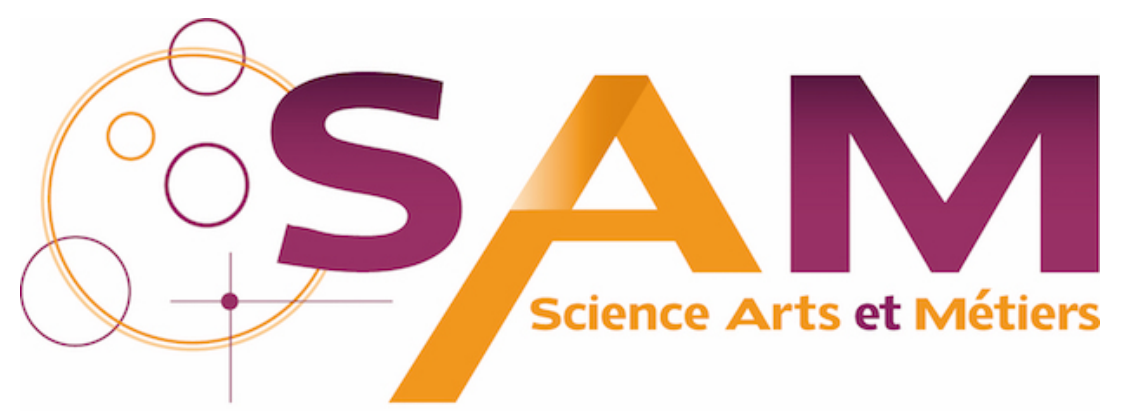

Archive Ouverte - Open Repository

\section{Science Arts \& Métiers (SAM)}

is an open access repository that collects the work of Arts et Métiers ParisTech researchers and makes it freely available over the web where possible.

This is an author-deposited version published in: https://sam.ensam.eu Handle ID: .http://hdl.handle.net/null

\section{To cite this version :}

Véronique FAVIER, Charles MAREAU, André GALTIER, Bastien WEBER, Marcel BERVEILLER Microstructure and self-heating for ferritic steels under cyclic loading at low stress magnitudes Revue de Metallurgie. Cahiers D'Informations Techniques - Vol. Volume 107, Issue 1, p.Pages 3$8-2010$ 


\title{
Microstructure and self-heating for ferritic steels under cyclic loading at low stress magnitudes ${ }^{\star}$
}

\author{
V. Favier ${ }^{1}$, C. Mareau², A. Galtier ${ }^{3}$, B. Weber ${ }^{4}$ and M. Berveiller ${ }^{2}$ \\ 1 Arts et Métiers ParisTech, CNRS, LIM, 151 Bd de I'Hôpital, 75013 Paris, France \\ 2 Arts et Métiers ParisTech, CNRS, LPMM, 4 Rue Augustin Fresnel, 57078 Metz Cedex 3, France \\ 3 CETIM, 52 Av. Félix-Louat, 60304 Senlis Cedex, France \\ 4 ArcelorMittal Maizières Research and Development, Voie Romaine, 57280 Maizières-lès-Metz, \\ France
}

\begin{abstract}
A new micromechanical modelling is proposed to correlate some microstructural parameters and dissipation in ferritic steels under cyclic loading. We assumed the occurrence of two dissipative mechanisms associated with anelastic and inelastic deformations, respectively. We showed that the modelling provides good qualitative prediction of the heating curves when changing the volume fraction of precipitates in ferritic steels. We highlighted the key role of the dispersion of the grain size on the local and global dissipation.
\end{abstract}

Résumé - Microstructure et auto-échauffement d'aciers ferritiques soumis à des sollicitations cycliques de faibles amplitudes de contraintes. Dans ce travail, nous proposons un nouveau modèle micromécanique à changement d'échelles pour décrire les relations entre certains paramètres microstructuraux (fraction volumique de précipités et taille de grain) et la dissipation intrinsèque d'aciers ferritiques soumis à des sollicitations cycliques. Ce modèle repose sur la prise en compte de deux mécanismes dissipatifs donnant lieu à des déformations, respectivement anélastique et inélastique. Ce modèle est capable de prédire qualitativement l'effet de la fraction volumique de précipités sur la dissipation. II met également en évidence le rôle très important de la dispersion de la taille de grain sur l'intensité de la dissipation au niveau local (grain) et au niveau macroscopique (polycristal).

$\mathrm{T}$

he rupture in high cycle fatigue is one of the main reasons for failure of parts in service. For steels, fatigue damage is caused by mechanisms related to the motion of dislocations. These mechanisms are dissipative and induce the self-heating of the specimen [1,2]. We consider that when the intrinsic dissipation is decreased due to changes in the microstructure, the fatigue limit increases. Consequently, in order to optimize the microstructure of steels for high cycle fatigue loadings, a better understanding of interactions between microstructure and intrinsic dissipation is required. The present work aims at analyzing and modelling the influence of some microstructural parameters such as the volume fraction of precipitates and the grain size on the dissipation in the case of ferritic steels.

\section{Dissipative mechanisms}

During cyclic loadings, the average (over the volume and over one loading cycle) dissipation per cycle $d$ can be estimated from temperature measurements in a stabilized thermal regime with the following relation $[3,4]$ :

$$
\frac{d}{m C_{p}}=\frac{\theta}{\tau}
$$

where $\theta$ is the average temperature increase per cycle in stabilized thermal regime. The dissipation is divided by the mass density $m$ and the specific heat $C_{p}$ so it is expressed in ${ }^{\circ} \mathrm{C} / \mathrm{s}$ rather than in $\mathrm{W} / \mathrm{m}^{3} . \tau$ is a time constant 


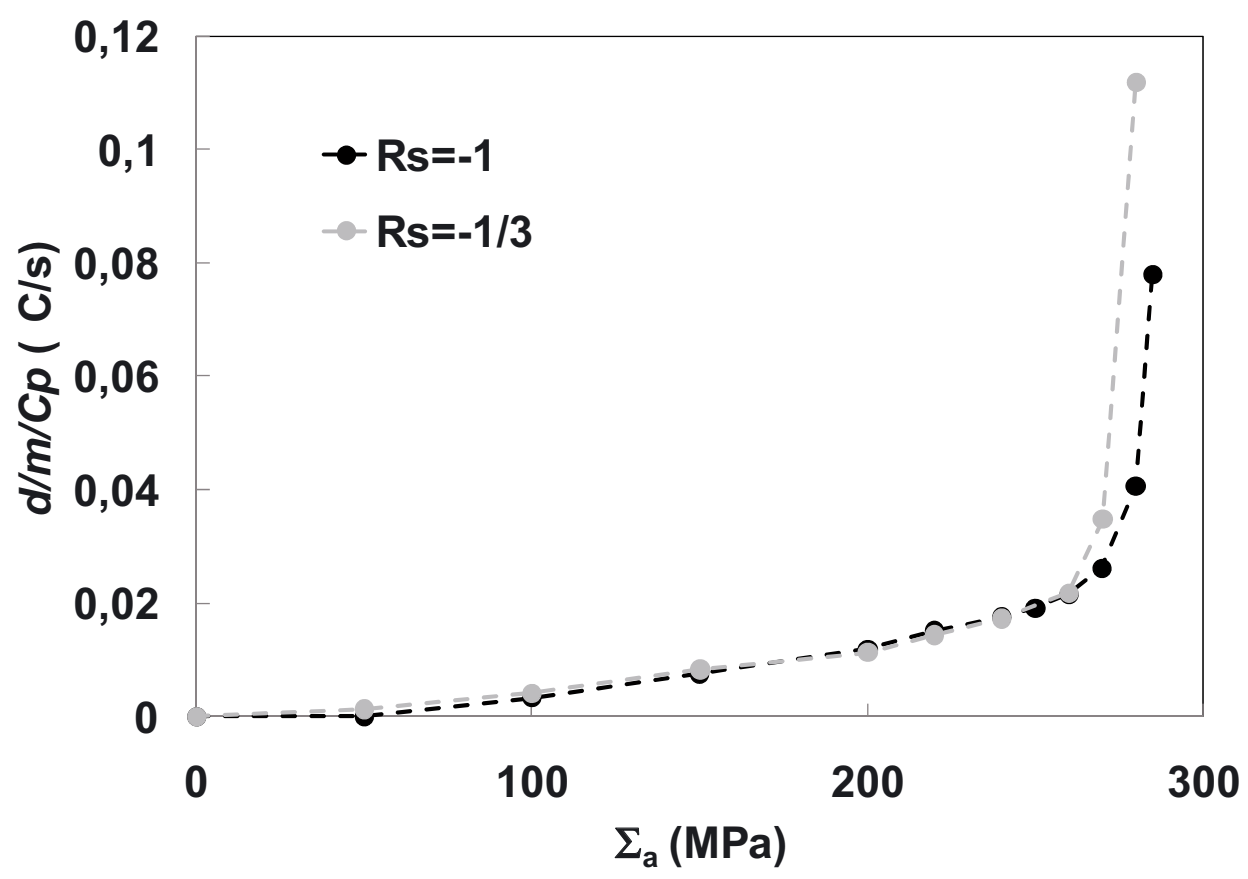

Fig. 1. Experimental heating curves obtained for a ferritic steel having precipitates (HSLA) for two loading ratio $\mathrm{Rs}$.

Fig. 1. Courbes d'échauffement expérimentales obtenues pour un acier ferritique contenant des précipités (HSLA) et pour deux rapports de charge Rs.

that characterizes the thermal exchanges between the sample and its environment and is easily determined during experiment [5]. $\frac{d}{m C_{p}}$ can be estimated for different increasing stress amplitudes $\Sigma_{a}$ for fixed loading ratio $R_{s}$ and frequency (30 Hz here). Figure 1 displays such data, called heating curves, for a ferritic steel having precipitates (labeled as HSLA for High Strength Low Alloys) for two $R_{s}$. We observe that for low $\Sigma_{a}, \frac{d}{m C_{p}}$ slowly increases with $\Sigma_{a}$ and does not depend on $R_{s}$. On the contrary, for higher $\Sigma_{a}, \frac{d}{m C_{p}}$ strongly increases with $\Sigma_{a}$ and depends on $R_{s}$ as similarly found by [6].

In a previous work [5], we suggested that the first regime of the heating curves is associated with anelastic (dissipative and recoverable) deformation within the material whereas the second regime results in inelastic (dissipative and unrecoverable) deformation. For modelling point of view, we considered that the anelastic deformation results in the motion of pinned dislocations viewed as damped vibrating string. This relaxation phenomenon was proposed initially by Koehler [7]. The associated strain is recoverable because the line tension brings the dislocation lines back in their equilibrium position. Besides, the displacements of the pinned dislocations are dissipative because of the lattice friction. The second regime is classically assumed to result in multiplication and glide of dislocations [1].

\section{Constitutive equations}

We consider a representative volume element (RVE) of ferritic steel polycrystals including a very large number of heterogeneities (grains). The single crystal constitutive equations are described using crystal plasticity framework. As a result, the flow rule for both anelastic and inelastic regimes are written on the slip systems. The overall behaviour is then deduced using a homogenisation scheme developed for elastic-anelastic-inelastic heterogeneous materials [8].

\section{Anelastic deformation}

The anelastic motion $\dot{\gamma}_{a n}^{g}$ of dislocations of the slip system $g$ is represented by equation 2 [9]:

$$
\dot{\gamma}_{a n}^{g}=\frac{1}{f}\left(\rho^{g} b^{2} \tau_{e f f}^{g}-8 \mu b^{2} \frac{\gamma_{a n}^{g}}{l^{2}}\right)
$$

where $f$ represents the lattice friction, $\mu$ the elastic shear modulus, $b$ the Burgers vector, $\rho^{g}$ is the dislocation density, $\tau_{\text {eff }}^{g}$ the effective shear stress, $\gamma_{a n}^{g}$ the anelastic slip $l^{g}$ and 
the mean distance between obstacles (determined using Friedel's work [10]) of the slip system $g$.

\section{Inelastic deformation}

\section{Flow rule}

The inelastic slip of $\dot{\gamma}_{a n}^{g}$ dislocations of the slip system $g$ is represented by a thermally activated flow rule [9]:

$$
\begin{aligned}
\dot{\gamma}_{\text {in }}^{g}=\dot{\gamma}_{0}\left(\frac{\tau_{\text {eff }}^{g}}{\mu}\right)^{2} \exp \left(\frac{-\Delta G_{0}}{k_{b} T}(1-\right. \\
\left.\left.\left(\frac{\left|\tau_{\text {eff }}^{g}\right|-\tau_{c}^{g}}{\hat{\tau}}\right)^{p}\right)^{q}\right) \operatorname{sign}\left(\tau_{\text {eff }}^{g}\right)
\end{aligned}
$$

where $\dot{\gamma}_{0}, p$ and $q$ are materials parameters, $\Delta G_{0}$ is the activation energy in a stress-free configuration, $T$ is the temperature, $k_{b}$ is the Boltzmann constant, $\hat{\tau}$ is the shear stress required to overcome Peierls obstacles at $T=0$ and $\tau_{c}^{g}$ is the critical shear stress from which viscoplastic slip is possible.

\section{Intragranular hardening}

Although dislocations of a given slip system do not have the same characteristics and so do not have the same response under loading, for the sake of simplicity, we assume that all the dislocations of the same slip system have the same behavior. The type of responses (anelastic or inelastic) is determined by the following equations:

$$
\begin{aligned}
& \dot{\gamma}^{g}=\dot{\gamma}_{a n}^{g} \text { for }\left|\tau_{\text {eff }}^{g}\right|<\tau_{c}^{g} \\
& \dot{\gamma}^{g}=\dot{\gamma}_{\text {in }}^{g} \text { for }\left|\tau_{e f f}^{g}\right| \geq \tau_{c}^{g} .
\end{aligned}
$$

The mathematical representation of the critical shear stress accounts for various types of obstacles and is written

$$
\tau_{c}^{g}=\tau_{c 0}^{g}+\frac{k}{\sqrt{D}}+\frac{1}{2} \mu b \sqrt{a^{g h} \rho^{h}}+\frac{\mu b}{r_{p}} \sqrt{\frac{3 f_{v}}{2 \pi}} .
$$

$\tau_{c 0}^{g}$ is the contribution of Peierls obstacles depending on the solute atom amount and nature. $\frac{k}{\sqrt{D}}$ represents the grain size effect where $D$ is the grain diameter and $k$ is a material parameter. $\frac{\mu b}{r_{p}} \sqrt{\frac{3 f_{v}}{2 \pi}}$ is the contribution of the non-shearable precipitates where $r_{p}$ is the radius of the assumed-spherical precipitates and $f_{v}$ is their volume fraction [11]. $\frac{1}{2} \mu b \sqrt{a^{g h} \rho^{h}}$ represents the hardening due to forest dislocations [12]. More details on equations are given in [9]. The dislocation densities change along with the deformation and follow equation 6 [13]

$$
\dot{\rho}^{g}=\frac{1}{b}\left(L^{g}-2 \gamma_{c} \rho^{g}\right)\left|\dot{\gamma}_{i n}^{g}\right|
$$

where $\gamma_{c}$ is the dislocation annihilation length and $L^{g}$ the mean free path of dislocations. $L^{g}$ depends on the grain size and decreases when dislocation densities increase as in

$$
\frac{1}{L^{g}}=\frac{1}{D}+\frac{\sqrt{a^{g h} \rho^{h}}}{K}
$$

where $K$ is a material parameter.

In addition to the intragranular isotropic hardening described by the evolution of $\tau_{c}^{g}$, we introduce intragranular kinematic hardening to represent long range obstacles such as grain size, dislocation walls... A back stress $x$ is calculated at the grain scale by means of equation 8 as proposed by [14]

$$
\dot{x}=\frac{2}{3} a_{c} \dot{\varepsilon}^{i n}-c_{c} x \sqrt{\frac{2}{3} \dot{\varepsilon}^{i n}: \dot{\varepsilon}^{i n}}
$$

where $a_{c}$ and $c_{c}$ are material parameters.

\section{Single-crystal constitutive equations}

Adopting the small perturbation theory, the local (grain) strain rate tensor $\dot{\varepsilon}$ is the sum of an elastic $\dot{\varepsilon}^{e}$, anelastic $\dot{\varepsilon}^{\text {an }}$ and inelastic $\dot{\varepsilon}^{\text {in }}$ strain rate tensors

$$
\dot{\varepsilon}=\dot{\varepsilon}^{e}+\dot{\varepsilon}^{a n}+\dot{\varepsilon}^{i n}
$$

where

$$
\begin{aligned}
\dot{\varepsilon}^{e} & =s: \dot{\sigma} \\
\dot{\varepsilon}^{a n} & =R^{g} \dot{\gamma}_{a n}^{g} \\
\dot{\varepsilon}^{i n} & =R^{g} \dot{\gamma}_{i n}^{g}
\end{aligned}
$$

$s$ is the local elastic compliance tensor (considered here as isotropic), $\dot{\sigma}$ is the stress rate tensor $R^{g}$ and is the Schmid tensor of the slip system $g$.

The effective shear stress $\tau_{\text {eff }}^{g}$ accounts for the local stress $\sigma$ resulting from the applied loading and the back stress $x$ and is written

$$
\tau_{\text {eff }}^{g}=R^{g}: \sigma-R^{g}: x
$$

The local stress rate $\dot{\sigma}$ is calculated from the applied macroscopic stress rate $\dot{\Sigma}$ and mechanical interactions between grains. The description of these interactions accounts for the elastic-anelastic-inelastic nature of the behaviour. The modelling used here is based on translated field techniques. The resulting interaction laws are not written in this paper but more details can be found in [8]. 
Table 1. Model for parameters for a HSLA steel grade with $f_{v}=$ 31 ppm.

Tableau 1. Paramètres du modèle pour un acier HSLA contenant une fraction volumique de précipités $f_{v}=31 \mathrm{ppm}$.

\begin{tabular}{lcccc}
\hline$\mu(\mathrm{MPa})$ & $\lambda(\mathrm{MPa})$ & $b(\mathrm{~m})$ & $1 / f(\mathrm{~Pa} . \mathrm{s})^{-1}$ & $\rho\left(\mathrm{m}^{-2}\right)$ \\
70000 & 105000 & $2,5.10^{-10}$ & 8000 & $10^{10}$ \\
\hline$\dot{\gamma} 0\left(\mathrm{~s}^{-1}\right)$ & $p$ & $q$ & $\Delta G_{0} / k_{b}(\mathrm{~K})$ & $T(\mathrm{~K})$ \\
9100 & 0,05 & 1 & 15000 & 293 \\
\hline$\hat{\tau}(\mathrm{MPa})$ & $\tau_{c 0}+k / \sqrt{d}(\mathrm{MPa})$ & $d(\mu \mathrm{m})$ & $f_{v}(\mathrm{ppm})$ & $r_{p}(\mathrm{~m})$ \\
50 & 60 & 13 & 31 & $5.10^{-9}$ \\
\hline$\alpha$ & $y_{c}(\mathrm{~m})$ & $K$ & $a_{c}(\mathrm{MPa})$ & $\mathcal{c}_{c}$ \\
0,5 & $4.10^{-8}$ & 80 & $1,8.10^{5}$ & 2200 \\
\hline
\end{tabular}

\section{Results}

\section{Influence of the precipitates}

First, we simulate the heating curves for ferritic steels having two volume fractions of precipitates (31 and $345 \mathrm{ppm}$ ) (HSLA). The size and the volume fraction of the precipitates and the mean grain size were obtained from microstructure observations. Other model parameters were identified using cyclic stress-strain curves in Low Cycle Fatigue (LCF) for different macroscopic strain magnitudes obtained for a HSLA steel grade with $f_{v}=31 \mathrm{ppm}$. Table 1 gives the value of all the parameters.

Next, heating curves for the two HSLA steel grades were simulated using the same model parameters except the volume fraction of precipitated which was changed to be consistent with the experimental values. As expected, the simulated heating curve matches well the experimental curve for the HSLA steel grade having $31 \mathrm{ppm}$ (used for the identification procedure) (Fig. 2). For the other grade $(345 \mathrm{ppm})$, a qualitative agreement is found between experimental and calculated data (Fig. 2). The dissipation is reduced in the first regime, with regards to results for HSLA with $31 \mathrm{ppm}$. In addition, the first regime is stretched to larger macroscopic stresses. Increasing the volume fraction of the precipitates results in shortening the pinned dislocation lines and as a consequence reduces the dissipation. Besides, the critical shear stress required to multiply dislocations increases with the volume fraction of precipitates. That is why the second regime of dissipation occurs for higher stresses. However some discrepancies appear between experimental and simulated results: the model underestimates the dissipation in the first regime and overestimates the dissipation in the second regime. These results are probably due to a too drastic representation of the transition between the anelastic and inelastic regimes.

\section{Influence of the grain size}

Figure 3 shows the impact of the grain size distribution on the heating curves. For these simulations, we consider three log-normal grain size distributions having the same mean grain size $\bar{D}$. The grain size distribution are characterized by the ratio $\frac{\Delta D}{D}$ (called as the relative dispersion in the following text) where $\Delta D$ is the standard deviation of the distribution.

We observe that the grain size distribution strongly affects the second regime of the heating curve. The higher the relative dispersion is, the higher the dissipation is. The biggest grains are responsible for such a result since dislocation glide is easier in coarse grains than in small grains. For $\Sigma_{a}=220 \mathrm{MPa}$, the modelling reveals that the smallest grains are still in the anelastic regime whereas the biggest grains display viscoplastic slip. Consequently the dissipation in the biggest grains is 30 times higher than the dissipation in the smallest grains. Considering the place of highest dissipation as microcrack initiation location, these results highlight the fact that not only the mean grain size but also the dispersion have to be controlled to increase fatigue properties.

\section{Conclusions}

A new micromechanical modelling was proposed to correlate some microstructural parameters and heating curve/dissipation in ferritic steels under cyclic loading. We assumed the occurrence of two dissipative mechanisms associated with anelastic and inelastic deformations, respectively. We showed that the modelling provides good qualitative prediction of the heating curves when changing the volume fraction of precipitates in ferritic steels. We highlighted the key role of the dispersion of the grain size on the local and global dissipation.

\section{References}

[1] A. Galtier, O. Bouaziz, A. Lambert, Mc. Ind, 8, 457-462

[2] C. Doudard, M. Poncelet, S. Calloch, C. Boue, F. Hild, A. Galtier, Int. J. Fatigue, 29 (2007) 748-757 


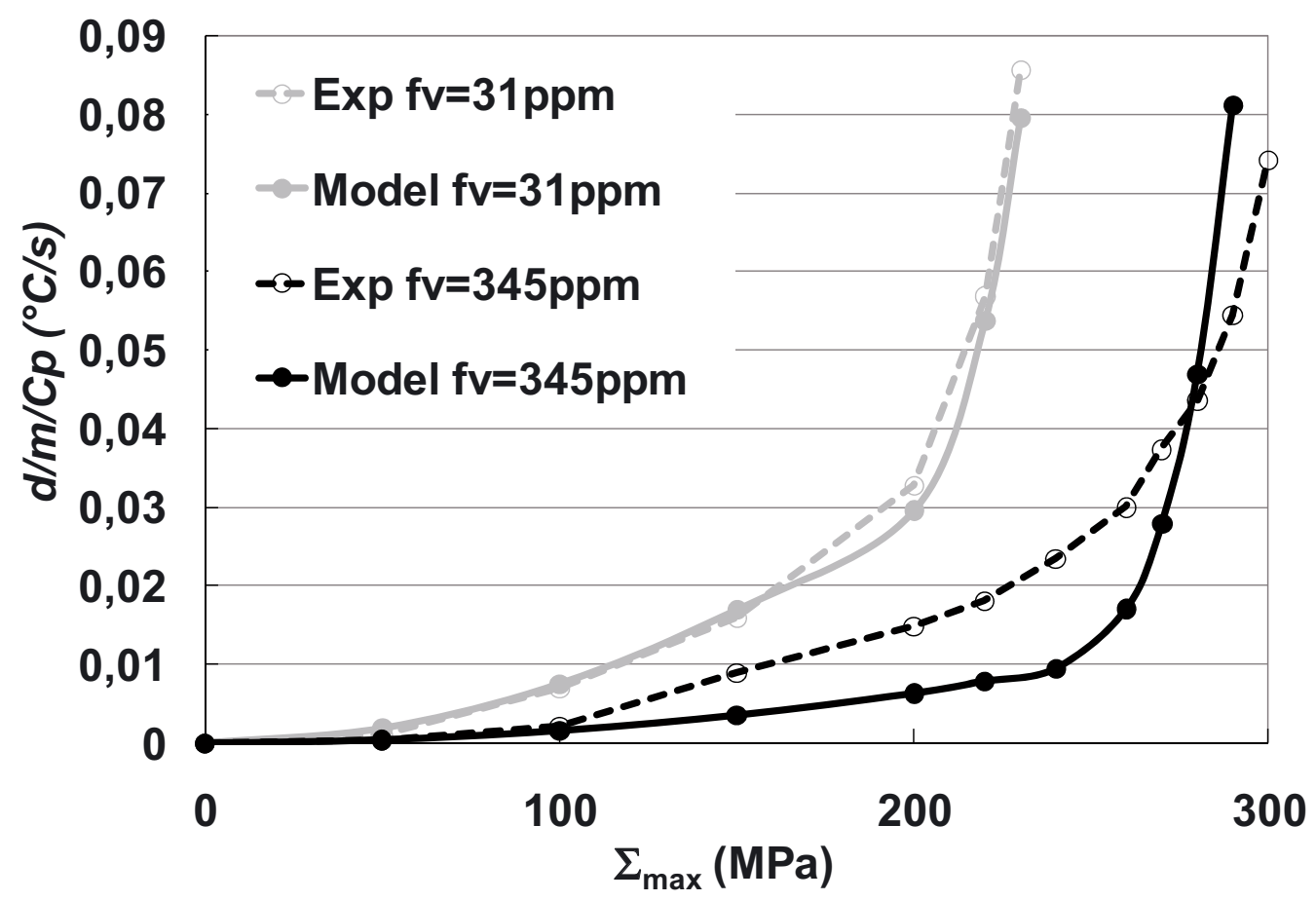

Fig. 2. Experimental (Exp) and calculated (Model) heating curves for two HSA steel grades having 31 and $345 p p m$, respectively.

Fig. 2. Courbes d'échauffement expérimentales (Exp) et calculées (Model) obtenues pour deux nuances d'aciers HSLA contenant des fractions volumiques de précipités égales à 31 and 345 ppm, respectivement.

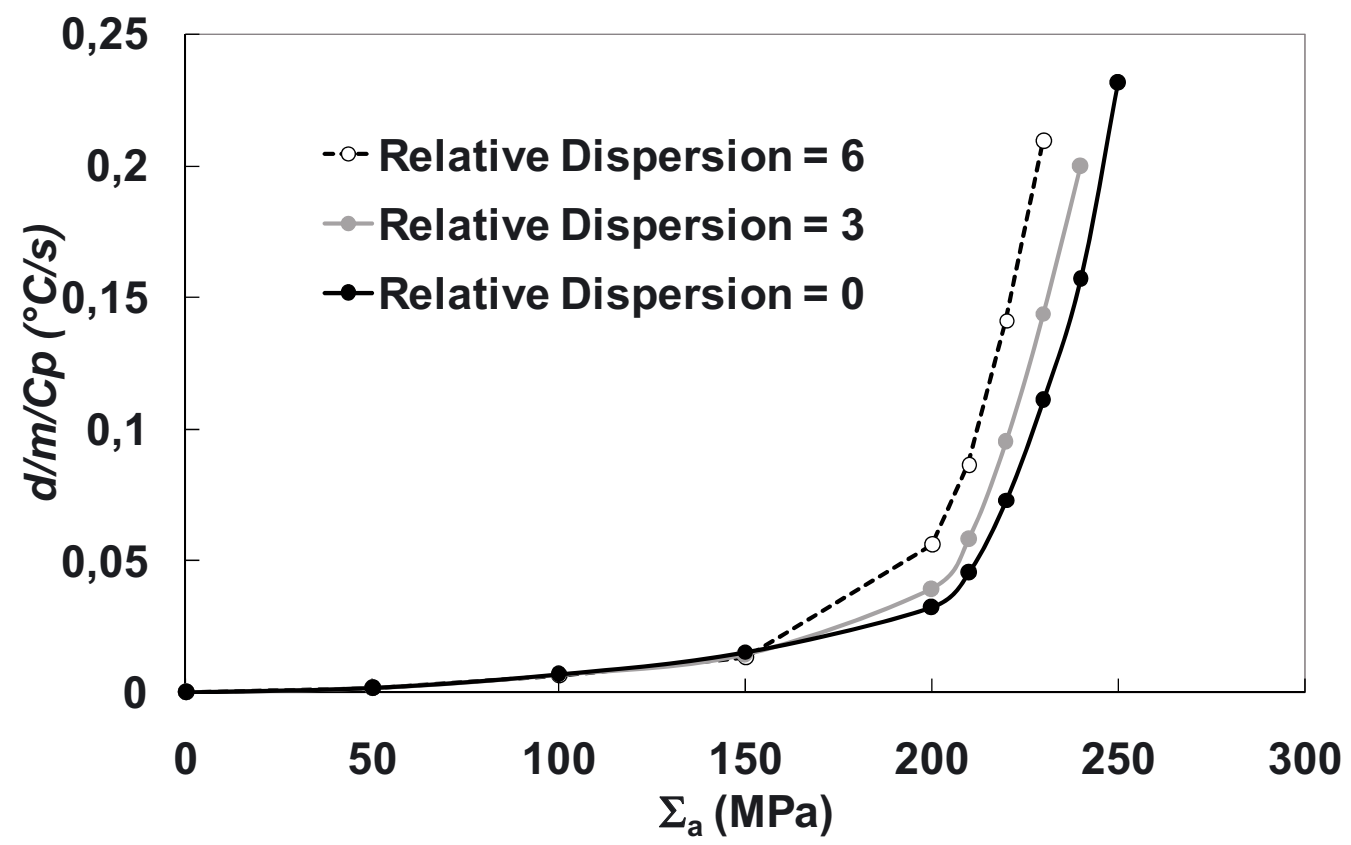

Fig. 3. Calculated heating curves for three grain size distributions having the same mean grain size.

Fig. 3. Courbes d'échauffement calculées pour trois distributions de taille de grain ayant une taille moyenne de grain identique. 
[3] H. Louche, A. Chrysochoos, Mater. Sci. Eng. A, 307 (1) (2001) 15-22

[4] T. Boulanger, Analyse par thermographie infrarouge des sources de chaleur induites par la fatigue des aciers, PhD thesis, Université Montpellier II, 2004

[5] C. Mareau, V. Favier, B. Weber, A. Galtier, Int. J. Fatigue, 31 (2) (2009) 1407-1412

[6] F. Maquin, F. Pierron, Mech. Mater, 41 (2009) 928-942

[7] J.S. Koehler, Imperfections in nearly perfect crystals. In W. Shockley, J.H. Hollomon, R. Maurer, F. Seitz (eds), New York, 1952, 197

[8] C. Mareau, V. Favier, M. Berveiller, Int. J. Solids Struct., 46 (2) (2009) 223-237
[9] C. Mareau, Modélisation de l'échauffement et de la microplasticité des aciers sous sollicitations cycliques, PhD thesis, ENSAM, 2007

[10] J. Friedel, Dislocations, Pergamon Press, Oxford, 1964

[11] A. Deschamps, Y. Brechet, Acta Mater 47 (1) (1998) 293-305

[12] U.F. Kocks, Phil. Mag., 13 (1966) 541-566

[13] H. Mecking, Strain hardening and dynamic recovery. Dislocation modelling of physical systems, Pergamon Press, N.Y., 1981, 197

[14] P.J. Armstrong, C.O. Frederick, A mathematical representation of the multiaxial Baushinger effect. Technical report RD/B/N 731, Central Electricity Generating Board, 1966 